\title{
Development of Osteogenic Cell Sheets for Bone Tissue Engineering Applications
}

\author{
Rogério P. Pirraco, ${ }^{1-3}$ Haruko Obokata, ${ }^{1,4}$ Takanori Iwata,, Alexandra P. Marques, ${ }^{2,3}$ \\ Satoshi Tsuneda, ${ }^{4}$ Masayuki Yamato, ${ }^{1}$ Rui L. Reis, ${ }^{2,3}$ and Teruo Okano ${ }^{1}$
}

The use of scaffolds in combination with osteogenic cells has been the gold standard in bone tissue engineering strategies. These strategies have, however, in many cases failed to produce the desired results due to issues such as the immunogenicity of the biomaterials used and cell necrosis at the bulk of the scaffold related to deficient oxygen and nutrients diffusion. Here, we originally propose the use of cell sheet (CS) engineering as a possible way to overcome some of these obstacles. Osteogenic CSs were fabricated by culturing rat bone marrow stromal cells in thermoresponsive culture dishes. The CSs were recovered from the dishes using a low-temperature treatment and then were implanted subcutaneously in nude mice. New bone formation was verified from day 7 post-transplantation using X-ray, microcomputed tomography, and histological analysis. The presence of a vascularized marrow was also verified in the newly formed bone after 6 weeks of transplantation. Further, osteocytes were found in this newly formed tissue, supporting the conclusion that mature bone was formed after ectopically transplanting osteogenic CSs. These results therefore confirm the great potentiality of CS engineering to be used in bone tissue engineering applications.

\section{Introduction}

$\mathbf{T}$ HE NUMBER OF PEOPLE who require medical intervention to solve bone-related illnesses such as nonunion fractures or loss of bone tissue caused by cancer tends to grow as a result of the constant aging of population. ${ }^{1-3}$ Currently, the gold-standard strategies to address issues like critical bone defects involve the use of autologous bone graft, allografts, and materials like ceramics and metals. ${ }^{1,3}$ All of these strategies have significant problems (e.g., scarce availability of tissues, donor-site morbidity issues, immunogenicity problems, and lack of integration in the host tissue) that limit their application range and their overall performance. ${ }^{1,5}$ It has been accepted for a few years that new strategies are needed to address the challenges posed in this field. Tissue engineering (TE)-based strategies have been trying to solve many of the above-referred problems. These approaches typically involve the use of different cell types suitable for bone TE, growth factors, and 3D biodegradable scaffolds. ${ }^{4,6}$ Such approaches, however, face in many cases serious problems such as inadequate biodegradability rate and the lack of vascularization, which leads to cell necrosis in the bulk of the construct. ${ }^{2,7-10}$
Cell sheet (CS) engineering technique using thermoresponsive dishes might constitute a useful alternative to solve some of the mentioned issues. This technique, as proposed by Professor Okano's group, allows for the recovery of the cells within its own matrix to be used as intact single, or multilayered, CSs to engineer transplantable tissues. ${ }^{11-13}$ So far this technology was proposed for the treatment of several tissues such as cornea, ${ }^{14}$ myocardium, ${ }^{15}$ periodontal ligament, ${ }^{16}$ and bladder, ${ }^{17}$ but never for bone. The peculiar mechanical and biological properties of bone tissue make the translation of the obtained outcomes from the regeneration of the above-mentioned tissues into bone, rather complicated. Others have previously attempted to produce CSs for the regeneration of bone tissue. ${ }^{18-20}$ Zhou et al..$^{20}$ wrapped osteogenic CSs made form porcine bone marrow stromal cells around polycaprolactone-calcium phosphate scaffolds. The postsubcutaneous implantation analysis of the construct showed some degree of new bone formation but mainly at the periphery of the scaffolds. The same pattern, around the scaffold, of new calcified tissue was achieved by Gao et al. ${ }^{19}$ using a coral scaffold, and by Akahane et al. ${ }^{18}$ using a hydroxyapatite ceramic scaffold. In the latter case, ${ }^{18}$ the CSs were also ectopically implanted without any scaffold, and

\footnotetext{
${ }^{1}$ Institute of Advanced Biomedical Engineering and Science, Tokyo Women's Medical University, Tokyo, Japan.

23B's Research Group-Biomaterials, Biodegradables, and Biomimetics, University of Minho, Headquarters of the European Institute of Excellence on Tissue Engineering and Regenerative Medicine, Guimarães, Portugal.

${ }^{3}$ PT Government Associated Laboratory, IBB-Institute for Biotechnology and Bioengineering, Guimarães, Portugal.

${ }^{4}$ Graduate School of Science and Engineering, Waseda University, Tokyo, Japan.
} 
new bone formation, though disorganized, was verified. The common outcomes of those three approaches were the formation of new bone tissue fairly disorganized, poorly vascularized, and limited to the surface of the scaffolds on where the CSs were wrapped. In contrast with the abovereferred works, where cells were detached using a cell scraper, the use of thermoresponsive dishes allows for the use of an intact cell-cell and cell-matrix architecture, due to the well-developed culture dish recovery method. ${ }^{12,13}$

In this work, we aimed at studying the in vivo bone formation potential of osteogenic CSs noninvasively recovered by temperature decrease. Osteogenic CSs were created from rat bone marrow stromal cells, cultured in thermoresponsive dishes, and then characterized. The developed sheets were subsequently transplanted subcutaneously to the dorsal flap of nude mice. Implants were recovered at different time points post-transplantation and characterized. New bone formation was apparent from 7 days postimplantation. Six weeks after implantation thick, newly vascularized bone with what appears to be bone marrow was clearly observed.

\section{Materials and Methods}

\section{Temperature-responsive culture surfaces}

Thermoresponsive dishes (CellSeed) were prepared as previously described ${ }^{21}$ Briefly, N-isopropylacrylamide monomer in 2-propanol solution was spread onto 35- $\mathrm{mm}$ diameter culture dishes (BD Biosciences). Dishes were then irradiated by electron beam, resulting in both polymerization and covalent grafting of the poly( $\mathrm{N}$-isopropylacrylamide $)$ (PIPAAm) onto the cell culture surfaces. PIPAAm-grafted dishes were rinsed with cold-distilled water to remove ungrafted monomer, and dried in nitrogen gas. Dishes were finally sterilized with ethylene oxide gas before experimental use.

\section{CS fabrication}

Bone marrow was flushed from the femurs of 4-week-old male Wistar rats (Charles River Japan). After vigorous pipetting to disaggregate any clumps, the suspension was placed over Histopaque 1083 (Sigma-Aldrich) and centrifuged at $2500 \mathrm{rpm}$ for $25 \mathrm{~min}$. The mononuclear cell fraction was recovered after centrifugation and washed in phosphate-buffered saline (Sigma-Aldrich) to remove any remaining Histopaque. Cells were then seeded in 100-mmdiameter tissue culture polystyrene dishes and cultured in basal medium (low-glucose DMEM; Wako Pure Chemical Industries), supplemented with $10 \%$ fetal bovine serum (Japan Bioserum Co. Ltd.) and 100 units $/ \mathrm{mL}$ of penicillinstreptomycin (Sigma-Aldrich Japan) at $37^{\circ} \mathrm{C}$ and in a $5 \%$ of $\mathrm{CO}_{2}$ humidified atmosphere. After $24 \mathrm{~h}$ of culture, nonadherent cells were removed from the culture and the adherent cells were then cultured until semiconfluence was achieved. Cells were detached using a $0.25 \%$ trypsin-EDTA solution (Gibco BRL LifeTechnologies) and seeded in $35 \mathrm{~mm}$ of diameter thermoresponsive dishes at a concentration of $2.5 \times 10^{5}$ cells per dish. Cultures were maintained for 3 weeks in the osteogenic medium (basal medium supplemented with $10^{-8} \mathrm{M}$ dexamethasone [Sigma-Aldrich], $50 \mu \mathrm{g} / \mathrm{mL}$ ascorbic acid [Sigma-Aldrich], and $10 \mathrm{mM} \beta$ glycerophosphate [Sigma-Aldrich]).

\section{Recovery of cells from thermoresponsive dishes}

To recover the cells from the thermoresponsive dishes, the culture medium was removed from the culture dishes and replaced with $1 \mathrm{~mL}$ of phosphate-buffered saline. A poly(vinylidene difluoride) (PVDF) (Immobilon-P, DURAPORE $^{\circledR}$; Millipore Corporation) membrane with a diameter of $20 \mathrm{~cm}$ was placed over the cells in the thermoresponsive dishes and incubated at $20^{\circ} \mathrm{C}$ for $10 \mathrm{~min}$. After this time, CSs spontaneously detached from thermoresponsive dishes. Some of the recovered CSs were fixed in $10 \%$ formalin (Wako Pure Chemicals) for posterior histological characterization.

\section{In vivo transplantation}

The transplantation of the CSs was carried out as reported previously. ${ }^{22}$ Briefly, 6-week-old male nude mice (Charles River Japan) (six animals per transplantation time) were anesthetized with a constant flux of $4 \%$ of isofluorane. Dorsal skin was cut opened using $3 \times 3 \mathrm{~cm}$ cutting sides. Recovered CSs were placed on mouse subcutaneous dorsal flap and left to adhere to the connective tissue of dorsal skin for $5 \mathrm{~min}$. After that time, the PVDF membranes were peeled off from the adhered CSs and silicone membranes were placed over the CSs to prevent the contact between the CSs and the muscular tissue. Control mice (three animals per transplantation time) were also prepared by implanting only silicone membranes. Skin incisions were closed using 5-0 nylon sutures. Animals were kept with food and water ad libitum. After 7 days, 3 weeks and 6 weeks of transplantation, animals were euthanized with $\mathrm{CO}_{2}$ and implants were recovered for histological characterization.

\section{Histological characterization}

After fixation, both in vitro recovered CS and implanted samples were embedded in paraffin, without demineralization, and 5 - $\mu \mathrm{m}$-thick sections were made. Hematoxylin and eosin staining was performed following standard protocols.

To assess mineral deposition alizarin red staining was performed. Briefly, a solution of $0.1 \%$ of alizarin red (Sigma-Aldrich) was made in $\mathrm{ddH}_{2} \mathrm{O}$ and the $\mathrm{pH}$ was adjusted to 4.6. Sections were deparaffinized and $1 \mathrm{~mL}$ of alizarin red solution was added to each slide. Sections were observed in the microscope until correct amount of color developed. Following that, slides were dipped three times in hematoxylin, washed thoroughly in water, de-hydrated, washed in xylene, and mounted with the mounting medium. Pink/purple color was considered positive for mineral deposition. Micrographs of the sections were taken after both stainings.

Immunostaining for osteocalcin was performed by incubating both the CS after in vitro culture and the implant sections with a $1 / 200$ anti-osteocalcin antibody (Millipore Corporation) overnight, at $4^{\circ} \mathrm{C}$, and then for $1 \mathrm{~h}$, room temperature, with a biotinylated secondary antibody (Dako Cytomation). Sections were incubated with streptavidinhorseradish peroxidase (DakoCytomation) solution for $20 \mathrm{~min}$ and then treated with DAB chromogenic substrate solution (DakoCytomation) for $3 \mathrm{~min}$.

Stained sections were analyzed with an Eclipse E800 microscope (Nikon). 


\section{DEVELOPMENT OF OSTEOGENIC CELL SHEETS}

\section{Microcomputed tomography}

To investigate the 3D structure of the mineralized tissue formed after transplantation, nondestructive techniques, X-ray and microcomputed tomography ( $\mu-\mathrm{CT})$ (SkyScan), were used. Recovered implants, after paraffin embedding, were cut in half and scanned in a high-resolution mode of $11.32 \mu \mathrm{m} \mathrm{x} / \mathrm{y} / \mathrm{z}$ and an exposure time of $1900 \mathrm{~ms}$. The energy of the scanner used was $50 \mathrm{keV}$ with a $171 \mathrm{~mA}$ current. The $\mu-C T$ scans were followed by a $3 \mathrm{D}$ reconstruction of serial images and quantification of the mineralized tissue using a minimum threshold value of 70 .

\section{Calcium quantification}

The samples analyzed by $\mu-C T$ were used for calcium quantification. Therefore, the halves of the recovered implants were weighted and incubated in $\mathrm{HCl} 0.5 \mathrm{M}$ to remove and dissolve the calcium. Calcium quantification in the obtained solutions was performed using the o-cresolphtaleincomplexon method with the Roche Cobas kit (Roche Diagnostics) following manufacturer's instructions. The absorbance of the samples was read at $570 \mathrm{~nm}$ in a microplate reader Synergy-HT (Bio-Tek). The calcium concentrations were extrapolated from the calibration curve obtained using serial dilutions of a calcium chloride solution and then normalized using the initial tissue mass.

\section{Statistical analysis}

Data were obtained from three separate experiments with three replicates for each condition and averaged. Standard deviation is reported as a measure of sample deviation. Statistical analysis of the calcium quantification and volume of mineralized tissue was performed using Student's $t$-test for $n=3$ and values were considered statistically significant for $p \leq 0.05$.

\section{Results}

\section{Osteogenic CS characterization}

The herein used CS engineering methodology allowed fabricating and recovering intact rat bone marrow-derived CSs composed by a dense collagenous matrix where cells are embedded (Fig. 1A). By the same micrograph observations, the estimated thickness of the CSs after recovery was of about $30 \mu \mathrm{m}$ (Fig. 1A).

Alizarin red staining was used to confirm the presence of calcium deposition and matrix mineralization in the cultured CSs (Fig. 1B). Significant calcium deposition in the cultured CSs was observed as evidenced by the intensity of the staining. Immunohistochemistry against osteocalcin showed high positivity for this protein especially in the CS matrix (Fig. 1C), confirming the osteogenic nature of the cultured and recovered CSs after temperature decrease.

\section{In vivo bone formation after CS transplantation}

Evidences of in vivo new bone formation after transplantation of the osteogenic CSs were confirmed by X-ray and

F2 $\mu-C T$ analysis (Fig. 2). After 7 days of transplantation the amount of dense tissue was already significant and a notorious increase in the density of the neo-bone was observed as the transplantation time increases.
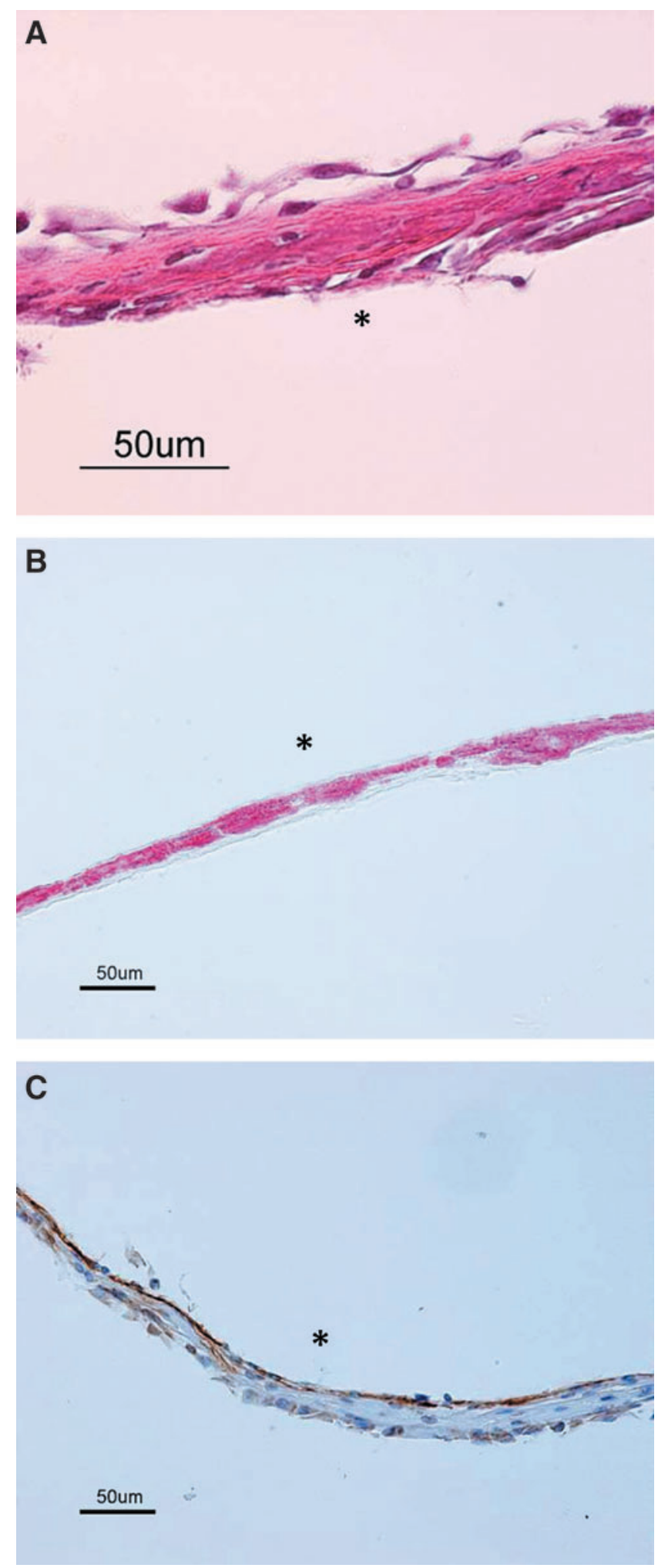

FIG. 1. In vitro cultured cell sheets after low-temperature recovery from thermoresponsive dishes characterized using (A) hematoxylin and eosin staining, (B) alizarin red staining (mineral deposition in purple), and (C) immunocytochemistry for osteocalcin (expression in brown). Asterisks mark the basal side of the cell sheets. Color images available online at www.liebertonline.com/ten. 

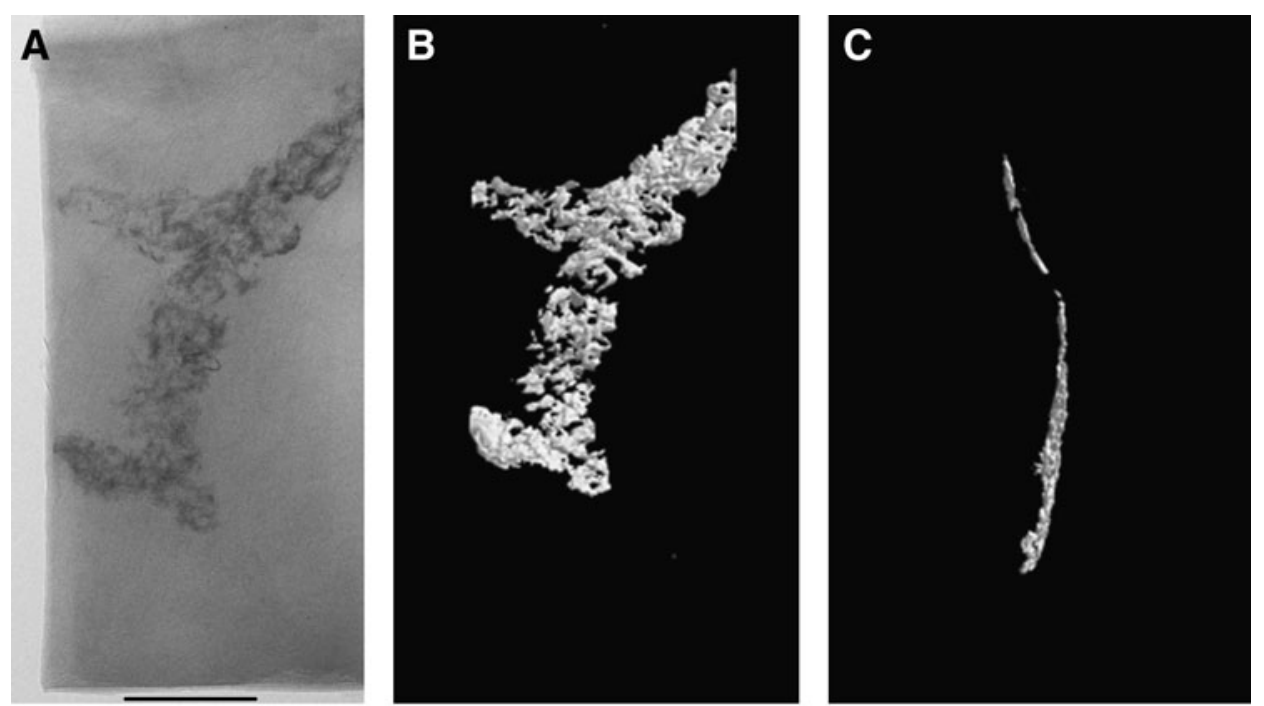

FIG. 2. Representative X-ray (A, D, G) and microcomputed tomography images (side [C, $\mathrm{F}, \mathrm{I}]$ and front view $[\mathrm{B}, \mathrm{E}, \mathrm{H}])$ of the transplants (each divided in half after recovery) after (A-C) 7 days, (D-F) 3 weeks, and (G-I) 6 weeks of implantation. Bars in the X-ray images represent $2 \mathrm{~mm}$ and are valid for all the images.
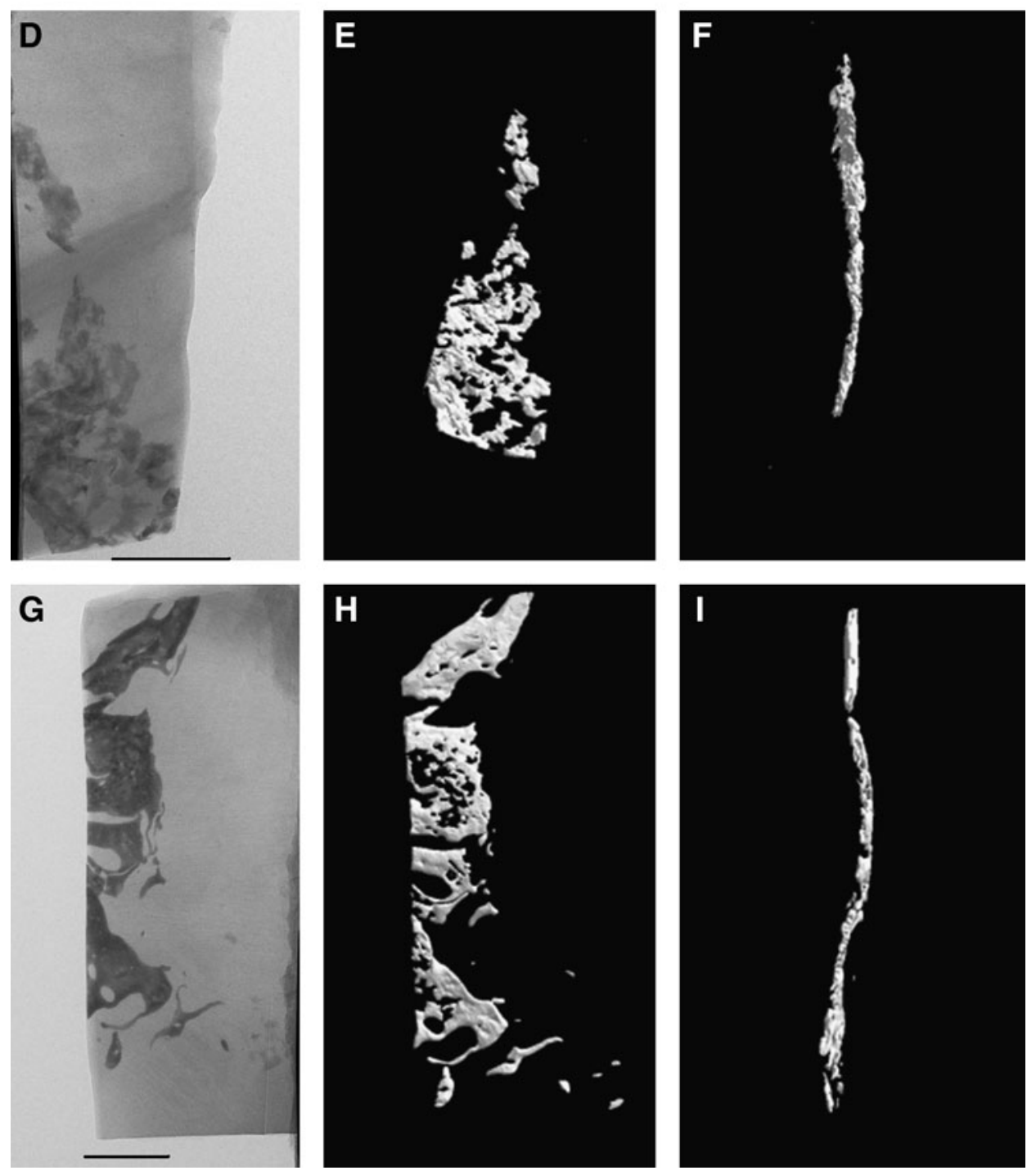


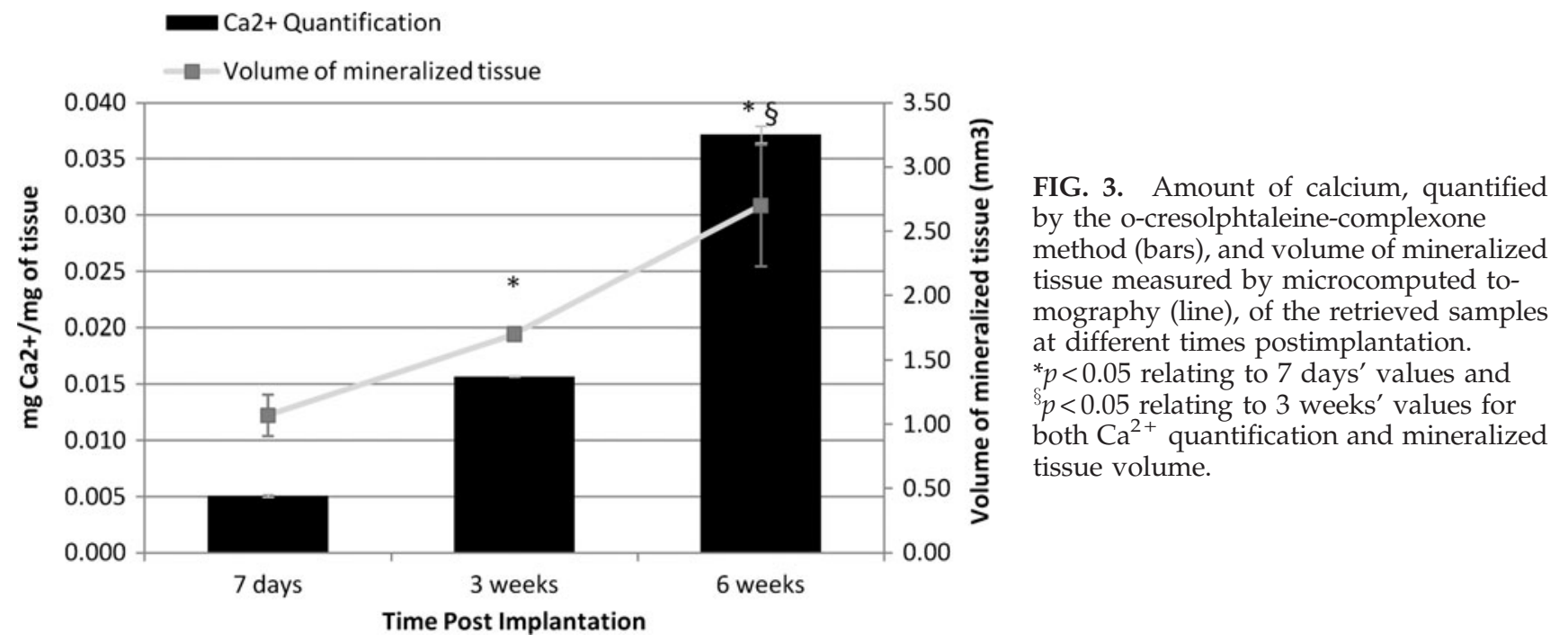

$\mu$-CT analysis was also employed to quantify the volume of

F3 the mineralized new tissue (Fig. 3). Results showed an increment in volume from $\sim 1 \mathrm{~mm}^{3}$ for day 7 of implantation to 2.7 for the 6 th week of implantation. This evolution in the quantity of new mineralized tissue was confirmed by calcium quantification (Fig. 3) using the o-cresolphtalein-complexon method. The detected amount of calcium per $\mathrm{mg}$ of tissue increased from $0.005 \mathrm{mg}$ to $0.0157 \mathrm{mg}$ and finally to $0.037 \mathrm{mg}$, respectively, at 7 days, 3 weeks, and 6 weeks postimplantation.

Alizarin red/hematoxylin and eosin staining of the in vivo samples allowed to observe mineralized tissue at the implant

F4 site just 7 days post-transplantation (Fig. 4A). The amount of new bone mineralized increased throughout the time of transplantation until it reached a maximum at 6 weeks posttransplantation (Fig. 4A-D). The new bone developed in what appears to be separated patches along the width of the subcutaneous dorsal flap. Six weeks after transplantation, numerous contiguous bone patches, with a maximum thickness of $250 \mu \mathrm{m}$ and a maximum width of $1 \mathrm{~mm}$ (Fig. 4C), were clearly observed. The patches contained a cellular marrow where numerous cells could be found, among which red blood cells (Fig. 4D). A detailed observation (Fig. 4E) permitted to identify osteocytes embedded in the sectioned mineralized tissue. Moreover, osteoid deposition was evident in some of the sections analyzed (Fig. 4F).

The immunohistochemistry results for osteocalcin showed that this protein was expressed at different locations even

F5 after only 7 days of transplantation (Fig. 5A). These positive sites seem to correlate to sites where new bone was being formed. With the increase of new bone formed with the transplantation time, it was clear that the majority of the cells that were positive for this protein were concentrated around the new tissue (Figs. 5B, C).

\section{Discussion}

The obtained CSs had the expected characteristics after osteogenic differentiation: collagen-rich, thick ECM with abounding mineralized areas. After exposure to a temperature below the lower critical solution temperature, the sheets slightly contracted, as described for other $\mathrm{CSs}^{23}$ due to contractile cytoskeleton forces. This means that the thickness of the CSs after detachment, as determined by histological analysis, was greater than when cells were attached, either to the surface or to the PVDF membrane. The presence of what appeared to be mineral deposits was clearly macroscopically identified in the sheets before its recovery from the thermoresponsive dishes. In fact, after the recovery of the CSs from the dishes, several mineral nodules were attached to the dish (data not shown), which was expected to happen considering the protocol used for the osteogenic differentiation. Further, osteocalcin, a noncollagenous matrix protein whose secretion correlates with matrix mineralization being therefore a marker for the osteogenic phenotype, ${ }^{24-26}$ was detected in high amount confirming the osteogenic nature of the developed CSs (Fig. 1B).

The transplantation of the fabricated CSs to the dorsal flap of nude mice resulted in the formation of bone mineralized tissue, whose volume greatly increased with time. These results also correlated with the amount of calcium quantified at each time point and with the strong staining for osteocalcin, which is an expected outcome because this protein is directly related to matrix mineralization and consequently to new bone formation. ${ }^{24-26}$

Histology results suggest that newly formed tissue organized in patches throughout the flap. By crossing theses results with the $\mu-C T 3 \mathrm{D}$ reconstruction, we could conclude that the observed patches were ramifications of the same bone mass. These bone masses had a flat form that may result from the original form of the CSs and/or from the local mechanical environment present in the mouse's subcutaneous site of transplantation, which determined the form of the new tissue. ${ }^{27,28}$

Osteoid formation was also visible in the in vivo histology results. As demonstrated before, ${ }^{29}$ ectopic bone formation by transplanted osteogenic cells is initiated by the deposition of osteoid. Osteoid is a partially mineralized immature bone that is eventually fully mineralized by osteogenic cells, thus becoming mature bone. Histological analysis demonstrated the presence of this immature bone proving that bone formation induced by the osteogenic CSs followed the accepted path of ectopic bone formation. ${ }^{29}$ Moreover, the newly 

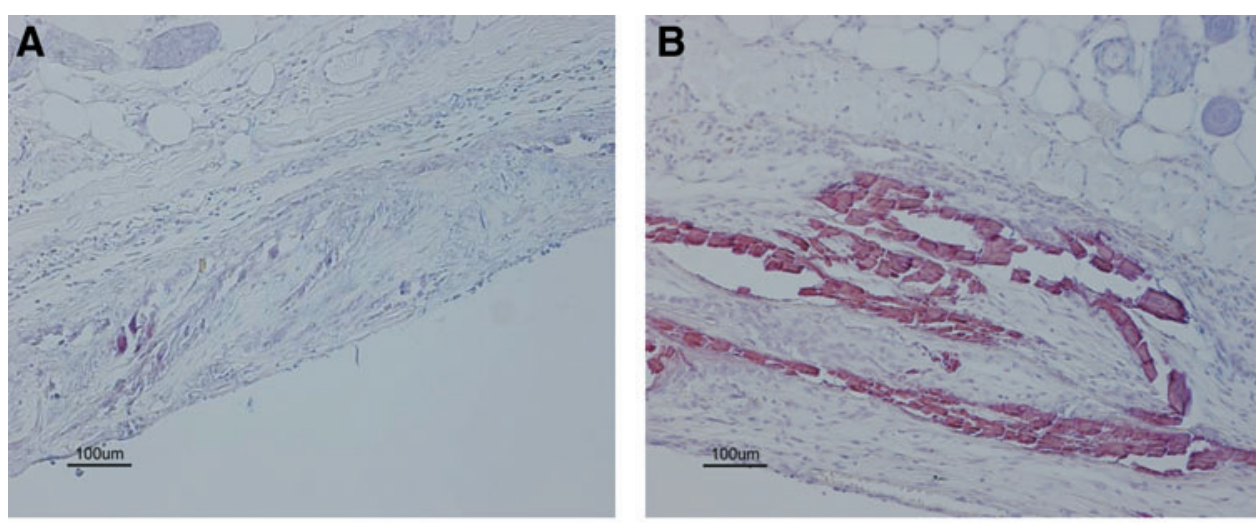

FIG. 4. Alizarin red and hematoxylin staining of the transplants sections recovered after (A) 7 days, (B) 3 weeks, and (C-F) 6 weeks of implantation. (D) and (E) are sequential close-ups of image (C). Yellow arrowheads in

(E) mark osteocytes and red arrowheads in (F) mark osteoid deposition. Mineral deposition is in purple. Color images available online at www.liebertonline.com/ten.
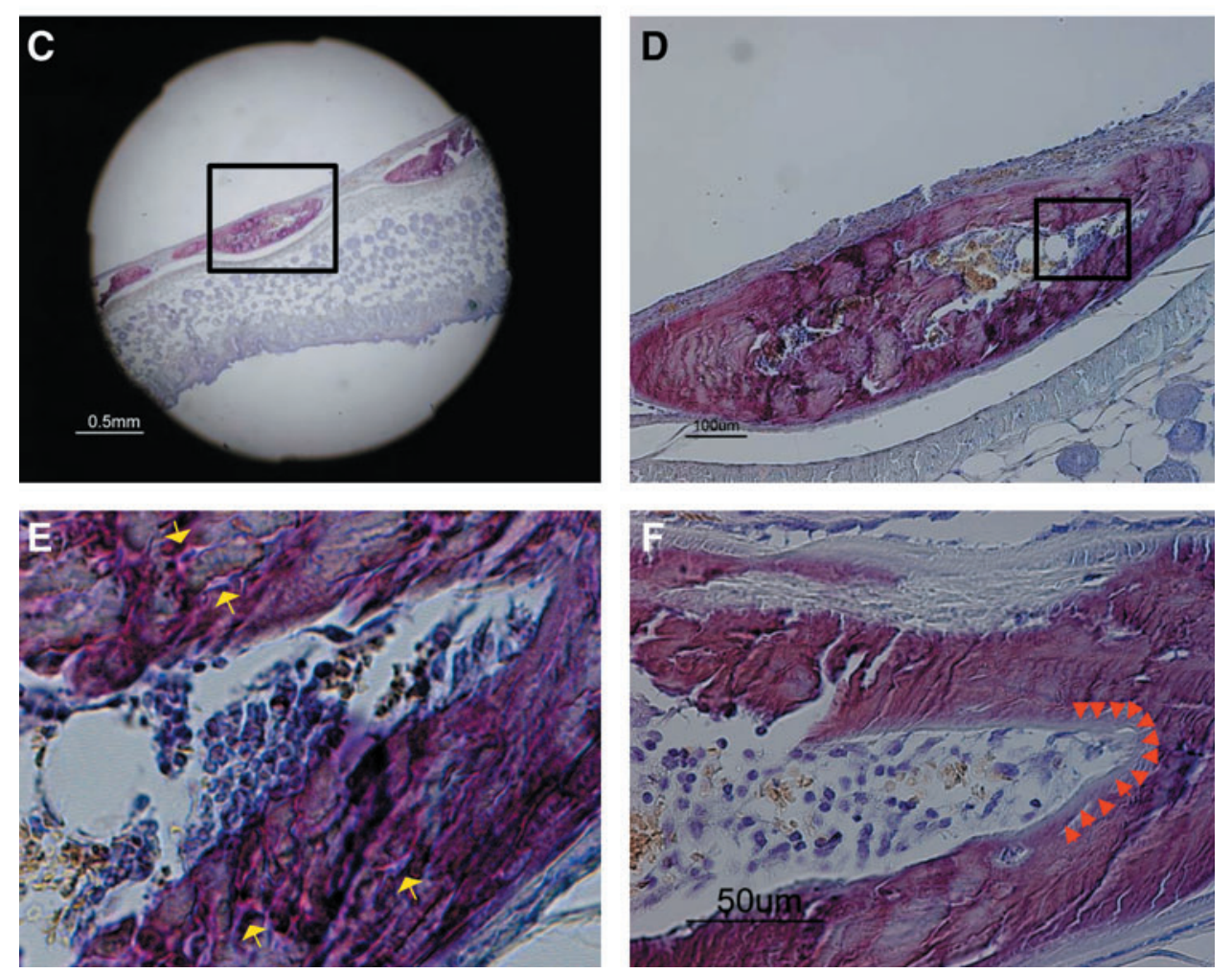

formed tissue presented a marrow space where multiple cells were observed. Erythrocytes were detected in that marrow, which might indicate the existence of erythropoiesis or the vascularization of that tissue. These observations and in particular the proven existence of a direct connection between vasculature and bone remodeling ${ }^{30-34}$ reinforce the hypothesis that the newly formed bone was being remodeled. Also very important to notice was the presence of osteocytes since, besides being the most common cells in bone tissue, these cells are believed to be the main regulators of bone homeostasis. ${ }^{35-37}$

Common approaches in bone TE include the use of osteoblasts or stem cell-derived osteoblasts, a scaffold as a 3D matrix, and growth factors. ${ }^{1,4,5}$ Scaffolds intend to support cell attachment and growth, and matrix production besides supplying mechanical resistance, considered extremely important for bone regeneration applications. ${ }^{1,4,5}$ Its use presents, however, problems related to cell migration to the interior of the scaffold as well as oxygen and nutrient dif- fusion limitations, ${ }^{7-10}$ impairing such strategies to achieve more successful outcomes. The gold standard in clinical settings continues to be the autologous bone grafts. ${ }^{4,5}$ This technique causes nonetheless severe donor-site morbidity ${ }^{4,5}$ and allogenic or xenogenic grafts have even more obvious limitations. ${ }^{4,5}$ CS engineering is a technique that if applied to bone regeneration can overcome many of the current limitations of those approaches.

Previous works that used osteogenic CSs in in vivo settings, ${ }^{18-20}$ either with or without scaffolds, have successfully induced the formation of new bone tissue. However, the newly formed tissue was in most cases either disorganized ${ }^{18}$ or incapable of growing in the interior of the scaffold ${ }^{19,20}$ due to the already described scaffold limitations. CS engineering avoids all of these shortcomings although, the lack of mechanical properties or the time span needed for the formation of an adequate bone volume might be considered as limitative. The most obvious application for osteogenic CSs would be flat bone defects such as cranial defects. The shape of the 

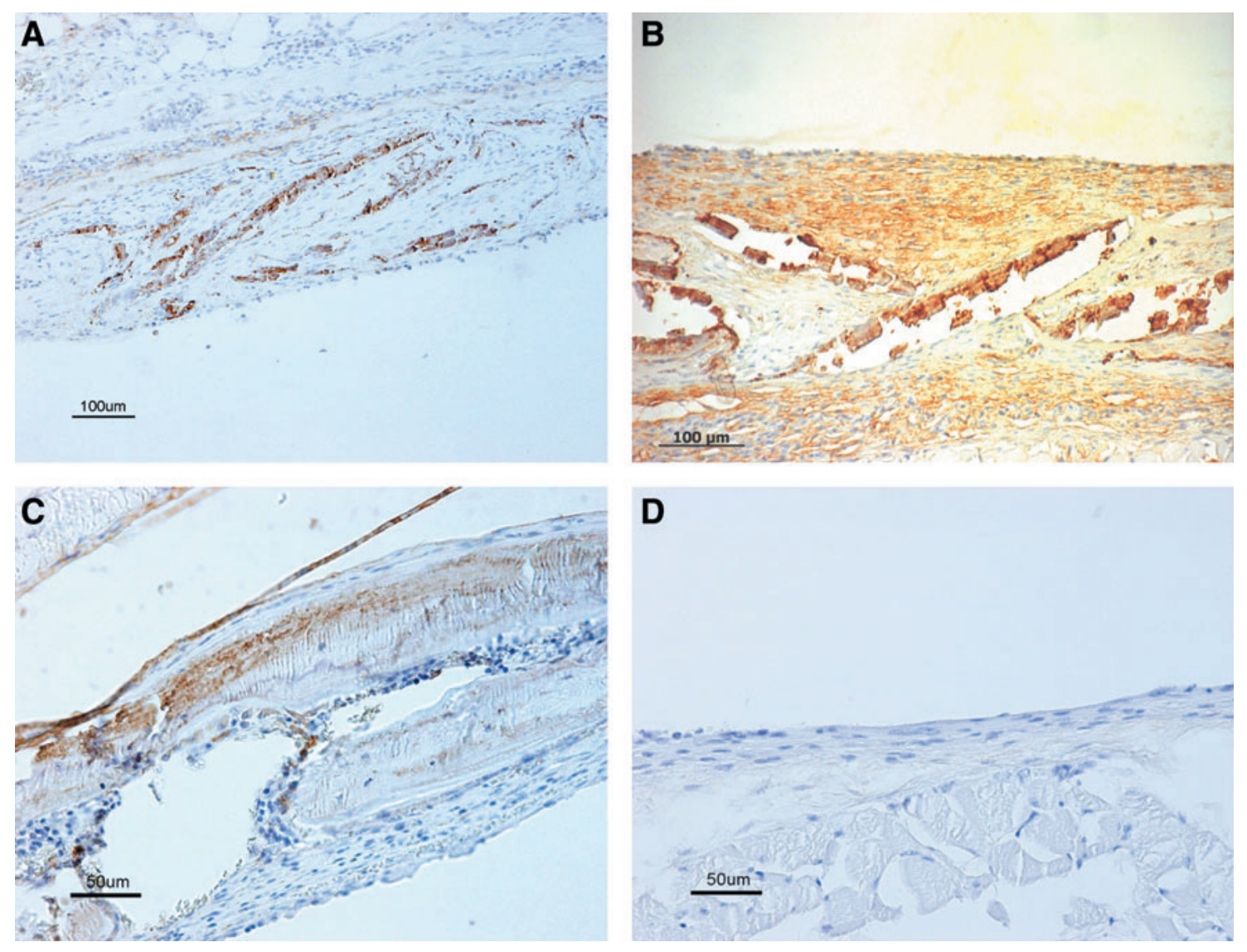

FIG. 5. Immunocytochemistry for osteocalcin in the transplants sections recovered after (A) 7 days, (B) 3 weeks, and (C) 6 weeks of implantation. (D) Corresponds to the negative control section obtained from the nude mice, where only the silicon membranes were implanted for 6 weeks. Color images available online at www.liebertonline.com/ten.

CSs and the possibility of stacking several sheets, as shown for other tissues, ${ }^{38,39}$ would allow a fast transplantation to such a defect. Further, the mechanical requirements of flat bones are less demanding than that of long bones, ${ }^{40}$ which avoids one of the possible limitation of CS engineering for bone regeneration. Nevertheless, in a recent article ${ }^{41}$ reserchers applied a CS recovered by cell scraper in a rat nonunion model by wrapping the sheet around the defect. This resulted in the regeneration of the defect in opposition to the group without CS. This work presents a possible way by which CSs can be applied to the regeneration of long bones. In this case the CSs were recovered using a cell scraper, and although cell-cell junctions are preserved using this method, the use of thermoresponsive dishes guarantees that both cell-matrix junctions and the ECM itself are preserved. ${ }^{12,13}$ The ECM can then act as natural glue that enables these sheets to be applied virtually in any anatomic site when implanted. Maeda et al. ${ }^{42}$ recently developed a device that allows a minimally invasive endoscopic transplantation of CSs fabricated in thermoresponsive dishes. Further developments of this method coupled with the attachment potential of the ECM open the way to deliver CSs, using a minimally invasive surgery, as de facto sheets for many applications, in opposition to the hypothesis of just injecting them, as suggested by other. ${ }^{18,41}$ Also, adequate bone volume can potentially be created by methods such as the overlay of several CSs combined with polysurgery, ${ }^{38}$ creat- ing thicker and bigger bone tissue. This specific issue will be addressed in future studies.

\section{Conclusions}

As already demonstrated for other tissues, CS engineering is also a very promising technique for bone TE applications. This work demonstrated that new bone tissue, with very interesting characteristics, namely, the presence of osteocytes, vascularization, and bone marrow formation, was formed from a single osteogenic CS. Three-dimensional neobone tissue was obtained in vivo without the use of any biodegradable scaffold and a new window of opportunity with great potential is open in the bone TE field.

\section{Acknowledgments}

This study was partially supported by Formation of Innovation Center for Fusion of Advanced Technologies in the Special Coordination Funds for Promoting Science and Technology "Cell Sheet Tissue Engineering Center (CSTEC)" and the Global COE program, Multidisciplinary Education and Research Center for Regenerative Medicine (MERCREM), from the Ministry of Education, Culture, Sports, Science and Technology (MEXT), Japan.

Financial support to R.P. Pirraco by the Portuguese Foundation for Science and Technology (FCT) through the $\mathrm{PhD}$ grant SFRH/BD/44893/2008 is also acknowledged. 


\section{Disclosure Statement}

No competing financial interests exist.

\section{References}

1. Dawson, J.I., and Oreffo, R.O.C. Bridging the regeneration gap: stem cells, biomaterials and clinical translation in bone tissue engineering. Arch Biochem Biophys 473, 124, 2008.

2. Pirraco, R.P., Marques, A.P., and Reis, R.L. Cell interactions in bone tissue engineering. J Cell Mol Med 14, 93, 2009.

3. Jordan, K.M., Sawyer, S., Coakley, P., Smith, H.E., Cooper, C., and Arden, N.K. The use of conventional and complementary treatments for knee osteoarthritis in the community. Rheumatology 43, 381, 2004.

4. Salgado, A.J., Coutinho, O.P., and Reis, R.L. Bone tissue engineering: state of the art and future trends. Macromol Biosci 4, 743, 2004

5. Kneser, U., Schaefer, D.J., Polykandriotis, E., and Horch, R.E. Tissue engineering of bone: the reconstructive surgeon's point of view. J Cell Mol Med 10, 7, 2006.

6. Nerem, R.M., and Sambanis, A. Tissue engineering: from biology to biological substitutes. Tissue Eng 1, 3, 1995.

7. Folkman, J., and Hochberg, M. Self-regulation of growth in three dimensions. J Exp Med 138, 745, 1973.

8. Kneser, U., Kaufmann, P.M., Fiegel, H.C., Pollok, J.M., Kluth, D., Herbst, H., et al. Long-term differentiated function of heterotopically transplanted hepatocytes on threedimensional polymer matrices. J Biomed Mater Res 47, 494, 1999.

9. Holy, C.E., Shoichet, M.S., and Davies, J.E. Engineering three-dimensional bone tissue in vitro using biodegradable scaffolds: investigating initial cell-seeding density and culture period. J Biomed Mater Res 51, 376, 2000.

10. Ishaug-Riley, S.L., Crane-Kruger, G.M., Yaszemski, M.J., and Mikos, A.G. Three-dimensional culture of rat calvarial osteoblasts in porous biodegradable polymers. Biomaterials 19, 1405, 1998.

11. Bittner, K., Vischer, P., Bartholmes, P., and Bruckner, P. Role of the subchondral vascular system in endochondral ossification: endothelial cells specifically derepress late differentiation in resting chondrocytes in vitro. Exp Cell Res 238, 491, 1998

12. Yamato, M., and Okano, T. Cell sheet engineering. Mater Today 7, 42, 2004

13. Yang, J., Yamato, M., Kohno, C., Nishimoto, A., Sekine, H., Fukai, F., et al. Cell sheet engineering: recreating tissues without biodegradable scaffolds. Biomaterials 26, 6415, 2005.

14. Nishida, K., Yamato, M., Hayashida, Y., Watanabe, K., Yamamoto, K., Adachi, E., et al. Corneal reconstruction with tissue-engineered cell sheets composed of autologous oral mucosal epithelium. N Engl J Med 351, 1187, 2004.

15. Shimizu, T., Yamato, M., Kikuchi, A., and Okano, T. Cell sheet engineering for myocardial tissue reconstruction. Biomaterials 24, 2309, 2003.

16. Hasegawa, M., Yamato, M., Kikuchi, A., Okano, T., and Ishikawa, I. Human periodontal ligament cell sheets can regenerate periodontal ligament tissue in an athymic rat model. Tissue Eng 11, 469, 2005.

17. Shiroyanagi, Y., Yamato, M., Yamazaki, Y., Toma, H., and Okano, T. Transplantable urothelial cell sheets harvested noninvasively from temperature-responsive culture surfaces by reducing temperature. Tissue Eng 9, 1005, 2003.

18. Akahane, M., Nakamura, A., Ohgushi, H., Shigematsu, H., Dohi, Y., and Takakura, Y. Osteogenic matrix sheet-cell transplantation using osteoblastic cell sheet resulted in bone formation without scaffold at an ectopic site. J Tissue Eng Regen Med 2, 196, 2008.

19. Gao, Z., Chen, F., Zhang, J., He, L., Cheng, X., Ma, Q., et al. Vitalisation of tubular coral scaffolds with cell sheets for regeneration of long bones: a preliminary study in nude mice. Br J Oral Maxillofac Surg 47, 116, 2009.

20. Zhou, Y., Chen, F., Ho, S.T., Woodruff, M.A., Lim, T.M., and Hutmacher, D.W. Combined marrow stromal cell-sheet techniques and high-strength biodegradable composite scaffolds for engineered functional bone grafts. Biomaterials 28, 814, 2007.

21. Hirose, M., Kwon, O.H., Yamato, M., Kikuchi, A., and Okano, T. Creation of designed shape cell sheets that are noninvasively harvested and moved onto another surface. Biomacromolecules 1, 377, 2000.

22. Obokata, H., Yamato, M., Yang, J., Nishida, K., Tsuneda, S., and Okano, T. Subcutaneous transplantation of autologous oral mucosal epithelial cell sheets fabricated on temperatureresponsive culture dishes. J Biomed Mater Res A 86, 1088, 2008.

23. Kushida, A., Yamato, M., Konno, C., Kikuchi, A., Sakurai, Y., and Okano, T. Temperature-responsive culture dishes allow nonenzymatic harvest of differentiated Madin-Darby canine kidney (MDCK) cell sheets. J Biomed Mater Res 51, 216, 2000.

24. Boston, M. High-resolution immunolocalization of osteopontin and osteocalcin in bone and cartilage during endochondral ossification in the chicken tibia. Anat $\operatorname{Rec} 234,479$, 1992.

25. Muraglia, A., Cancedda, R., and Quarto, R. Clonal mesenchymal progenitors from human bone marrow differentiate in vitro according to a hierarchical model. J Cell Sci 113, 1161, 2000.

26. Stein, G.S., and Lian, J.B. Molecular mechanisms mediating proliferation/differentiation interrelationships during progressive development of the osteoblast phenotype. Endocr Rev 14, 424, 1993.

27. Huiskes, R., Ruimerman, R., van Lenthe, G.H., and Janssen, J.D. Effects of mechanical forces on maintenance and adaptation of form in trabecular bone. Nature 405, 704, 2000.

28. Wolff, J. The law of bone remodeling. (Das Gesetz der Transformation der Knochen, Kirschwald, 1892). Translated by Maquet, P., and Furlong, R. Berlin: Springer-Verlag, 1986.

29. Okumura, M., Ohgushi, H., Dohi, Y., Katuda, T., Tamai, S., Koerten, H.K., et al. Osteoblastic phenotype expression on the surface of hydroxyapatite ceramics. J Biomed Mater Res 37, 122, 1997.

30. Collin-Osdoby, P. Role of vascular endothelial cells in bone biology. J Cell Biochem 55, 304, 1994.

31. Kanczler, J.M., and Oreffo, R.O.C. Osteogenesis and angiogenesis: the potential for engineering bone. Eur Cell Mater 15, 100, 2008.

32. Parfitt, A.M. Osteonal and hemi-osteonal remodeling: the spatial and temporal framework for signal traffic in adult human bone. J Cell Biochem 55, 273, 1994.

33. Parfitt, A.M. Skeletal heterogeneity and the purposes of bone remodeling: implications for the understanding of osteoporosis. In: Marcus, R., Feldman, D., Nelson, D.A., and Rosen, C.J., eds. Osteoporosis, 2nd edition. San Diego: Academic Press, 2008, pp. 315-329.

34. Streeten, E.A., and Brandi, M.L. Biology of bone endothelial cells. Bone Miner 10, 85, 1990. 


\section{DEVELOPMENT OF OSTEOGENIC CELL SHEETS}

35. Kamioka, H., Honjo, T., and Takano-Yamamoto, T. A threedimensional distribution of osteocyte processes revealed by the combination of confocal laser scanning microscopy and differential interference contrast microscopy. Bone 28, 145, 2001.

36. Nijweide, P.J., Burger, E.H., Nulend, J.K., and Van der Plas, A. The osteocyte. In: Bilezikian, J.P., Raisz, L., and Rodan, G.A., eds. Principles of Bone Biology. San Diego: Academic Press, 1996, pp. 115-126.

37. Palumbo, C., Palazzini, S., and Marotti, G. Morphological study of intercellular junctions during osteocyte differentiation. Bone 11, 401, 1990.

38. Shimizu, T., Sekine, H., Yang, J., Isoi, Y., Yamato, M., Kikuchi, A., et al. Polysurgery of cell sheet grafts overcomes diffusion limits to produce thick, vascularized myocardial tissues. FASEB J 20, 708, 2006.

39. Iwata, T., Yamato, M., Tsuchioka, H., Takagi, R., Mukobata, S., Washio, K., et al. Periodontal regeneration with multilayered periodontal ligament-derived cell sheets in a canine model. Biomaterials 30, 2716, 2009.

40. Mao, J.J., Giannobile, W.V., Helms, J.A., Hollister, S.J., Krebsbach, P.H., Longaker, M.T., et al. Craniofacial tissue engineering by stem cells. J Dent Res 85, 966, 2006.
41. Nakamura, A., Akahane, M., Shigematsu, H., Tadokoro, M., Morita, Y., Ohgushi, H., et al. Cell sheet transplantation of cultured mesenchymal stem cells enhances bone formation in a rat nonunion model. Bone 46, 418, 2010.

42. Maeda, M., Yamato, M., Kanzaki, M., Iseki, H., and Okano, T. Thoracoscopic cell sheet transplantation with a novel device. J Tissue Eng Regen Med 3, 255, 2009.

Address correspondence to:

Teruo Okano Institute of Advanced Biomedical Engineering and Science Tokyo Women's Medical University 8-1 Kawada-cho,Shinjuku-ku Tokyo 162-8666 Japan

E-mail: tokano@abmes.twmu.ac.jp

Received: August 10, 2010 Accepted: January 25, 2011 Online Publication Date: 


\section{AUTHOR QUERY FOR TEA-2010-0470-VER9-PIRRACO_1P}

AU1: Please mention authors' degrees.

AU2: Please expand DMEM and DAB.

AU3: Please mention the degrees of the corresponding author.

AU1 - R.P. Pirraco B.Sc.

H. Obokata M.S.

T. Iwata Ph.D.

A.P. Marques Ph.D.

S. Tsuneda Ph.D.

M Yamato Ph.D.

R.L. Reis Ph.D.

T. Okano Ph.D.

AU2 - DMEM: Dulbecco's Modified Eagle's Medium

DAB: 3,3'-diaminobenzidine

\section{AU3 - Teruo Okano, Ph.D.}

